http://dx.doi.org/10.4314/ejotmas.v7i1-2.3

\title{
INTERACTIVE THEATRE FOR COMMUNITY CONFLICT RESOLUTION AND TRANSFORMATION: THE OYE-EKITI FORUM THEATRE WORKSHOP IN PERSPECTIVE
}

\author{
*Joseph Agofure IDOGHO, Ph.D.
}

\begin{abstract}
The violent conflicts between the students of Federal University OyeEkiti (FUOYE) and their host community, Oye-Ekiti and other neighbouring communities where students reside - Ayegbaju-Ekiti, Ilupeju-Ekiti, Itapa and Ikole-Ekiti, as witnessed in recent times have been of a great concern to all and sundry. Interestingly, the viability of drama or theatre as a conflict transformation and resolution tool has continued to gain ground since the twentieth century. It is against the backdrop of using drama for conflict resolution (DCT), therefore, that this paper argues that forum theatre (FT) is an artistic methodology for participatory citizenship that creates a process of collective reflection to produce solutions to community conflicts. The study is theoretically hinged on Mezirow's transformative learning theory. The theory explains the change process that transforms the human frames of reference to explain Boal's FT techniques. The techniques give the ordinary people the opportunity to be part of their problems and to find ways to resolve them by themselves. The study adopts qualitative approach, using forum theatre workshop and participant observation in its data gathering and descriptive approach in its data presentation and analysis. The findings revealed that interactive/participatory theatre which forum theatre is a component of possesses the potency for communities' conflict transformation and resolution when properly applied. The study, therefore, recommends that theatre practitioners and scholars should leverage on interactive/participatory theatre as a tool for projecting good and exemplary governance
\end{abstract}

Keywords: FT, Transformative learning theory, Community participation, FUOYE, DCT

\footnotetext{
*Joseph Agofure IDOGHO, Ph.D. is of the Department of Theatre and Media Arts, Federal University, Oye-Ekiti, Nigeria

Email: joseph.idogho@fuoye.edu.ng
} 


\section{Introduction}

Students' aggressive behaviour at school remains a significant threat to safe learning environment. Oye-Ekiti particularly witnessed destructive violent conflicts in May, 2018, which led to the closure of the Federal University for two weeks. These conflicts created an atmosphere of tension, mistrust, fear and suspicion which threatened inter-community harmony among the people - the FUOYE students, strangers in the town and the indigenes otherwise known as 'Omonile'. The conflicts resulted in insecurity, movement restriction, landlords versus students-tenants mistrust and students-indigenes clashes, among others. The outcome of these violent conflicts seriously affected relationships between FUOYE students and their landlords in the host communities. The sour relationships engendered by these conflicts form the problem of this study. Drama/theatre has been an age-long tool for conflict resolution. It is in this connection that this study examines the potency of drama/theatre in resolving the FUOYE students/OyeEkiti indigenes incessant conflicts. The issue, if not properly addressed, will constitute threat in the nearest future and may become a fertile ground for recurrences of violent conflicts. The focus of this study, therefore, is to explore how FT practice can help the affected areas and people in the areas - Oye-Ekiti, Ayegbaju-Ekiti, Ilupeju-Ekiti, Itapa and Ikole-Ekiti to build sustainable peace.

The word conflict conjures associations of tension, disruption, and violence with the expectation of anything from uncomfortable to life-threatening situations. From such a perspective, conflict is something to be avoided or even suppressed. However, there is another side to; which is the bringing of an unjust situation to the surface or public arena, the deliberate instigation of violence among students themselves or students against indigenes. Thus the interaction between the FUOYE students and the host communities' indigenes cannot be violent-free, since they are adolescents. Therefore conflict in itself cannot be eliminated, but ways need to be developed to handle conflict which liberate its creative potential and curtail its destructive manifestations. It is in the light of the foregoing that this study experiment with forum theatre to stimulate and serve as alternative medium to look for creative solutions and the challenging of outmoded ideas and patterns of thinking. In this way conflict can be a spur to creativity and development and can lead to a higher synthesis beyond contending views or positions. Thus, the question of insecurity is rampant and FT as a tool for building has to be employed to step in as a matter of urgency. 


\section{Objectives of the Study}

The broad aim of this study is to examine the potency of drama for conflict resolution as a viable pedagogical tool to lessen adolescent aggressive behaviour and educate parties in conflict on dialogue and resolution. The study sets out the following objectives to achieve its aim:

i. to ascertain if drama for conflict resolution programmes increases adolescents/youths knowledge regarding effective strategies for conflict resolution;

ii. to ascertain if drama for conflict resolution programmes would help decrease adolescent/ youths' aggression level; and

iii. to ascertain if drama for conflict resolution programmes would help increase and improve on adolescent/youths' level of effective communication, which could prevent conflict situations. These objectives formed the basis of the discussions in the subsequent section.

\section{Research Method}

This study adopts qualitative research approach by carrying out a drama for conflict resolution programme (workshop) with participants; thereby using participant observation approach for its data gathering. Participants: the population of interest included the entire 200 level students (One Hundred and Ten (110) adolescents, consisting of (68) male and (42) females, ages 18-25 years) of the 2017/2018 session of the Department of Theatre and Media Arts, FUOYE and (Eighty (80) adolescents and youths between the ages of (18 - 55 years), consisting of 42 females and 38 males) gathered from Irona Quarters, Oye-Ekiti. A pre-post measure was developed using a participatory evaluation approach (McTaggart, 1997) and in conjunction with the programme facilitators to measure attitudes and knowledge regarding conflict resolution. The measure included 15 Likert scale items that assess attitudes regarding conflict resolution,

\section{Conceptual Clarification}

Interactive theatre is a flexible set of games, exercises, and techniques that are used to create dialogue on issues of concern in a community. Interactive theatre is sometimes called "participatory theatre", "transformative theatre" or "community-based theatre," or when it is applied to work with conflict issues, as captured in this study it is called "drama for conflict transformation". Interactive theatre has been in use since 20th century; its origin could be traced to the works of Paulo 
Freire and Augusto Boal in Brazil and it has also been put to use in other parts of the world such as North America, Asia, Europe, Africa, and Australia (Baim, Sally \& Alun 2002, p.28). It has been used in urban and in rural areas, and in diverse settings such as schools and universities, rehabilitation centres, orphanages, correction facilities, and community development centres.

Interactive theatre is packaged in various techniques including: image theatre, invisible theatre, playback theatre, legislative theatre, forum theatre, etc. These techniques are rooted in the theatre practice by a Brazilian theatre director named Augusto Boal. After a military coup in 1968, Boal developed dramatic exercises to engage the populace in creating their desired future by staging and rehearsing problems they faced and their potential solutions. These exercises used theatrical devices which established dialogue and community problem solving. Boal created Forum theatre (FT) in an effort to break down the "invisible wall" between the actors and audience in theatre. The goal is for audience members to develop action plans towards the resolution of actual conflicts through dramatic interventions. The spectator of the drama does not only watch the performance, but also acts—becoming what Boal called the "spect-actor." However, this study focuses on the deployment of Forum Theatre (FT) as tool for community conflict resolution and transformation in Oye-Ekiti.

FT is a theatre technique that is opened to everyone, for amateur actors and other professionally trained artists. It is a theatre that is at the service of ordinary people. It is aimed at democratizing peoples' access to art and culture not only as passive consumers but as active participants as creators in the process re-discovering their inherent creative potential. Forum theatre is also an entirely community-driven process, in which people from different walks of life come together to collectively discuss important community issues, develop interactive plays about these issues and act out these plays in front of other people like them in order to search for grassroots solutions. The focus of the performance lies as much on the audience as on the actors on stage. To this end, the preoccupation of FT is not art per se but the mobilization of ordinary ('oppressed' or 'marginalized') people to take control of their own lives and become powerful agents of change for the transformation of their community. In other words, forum theatre is a predominantly political and social rather than an artistic tool, though it is ultimately the combination of politics and art that makes it such a unique and innovative methodology. This has led many Nigerian theatre scholars (Umar-Idegu 2006, Buratai, 2008, Daniel, 2008) to question the difference between FT and conventional theatre. The crux of their debates hinge on the fact that conventional theatre itself 
is transformative and by so doing there is no clear-cut demarcation in the functionality of the theatre.

Arguably the main difference is that conventional theatre is more often than not a top-down process in which most, if not all, of the aspects related to the production are the exclusive domain of theatre professionals, with the audience assigned the role of passive spectators, recipients of other people's work and ideas. In FT, on the other hand, the focus is on providing opportunities for ordinary people who might have never thought of themselves as actors to reappropriate the theatrical means of production and to use these theatrical means to start transforming society. In the words of Augusto Boal (2000: iv), "theatre is a form of knowledge; it should and can also be a means of transforming society." At the same time, it is important to emphasize that FT is not an effective tool when it comes to simply wanting to pass a particular message to the audience, i.e., when the goal is to educate people about a particular issue or desired behavioural change. Forum theatre performances always revolve around questions rather than answers, and the idea is to empower communities to find their own solutions instead of letting others decide what is good for them.

This notion of supporting self-help is intimately linked to the theory and practice of renowned Brazilian pedagogue Paulo Freire. Working with largely illiterate, impoverished communities in Brazil and other parts of Latin America in the 1970s, Freire was interested in nourishing a pedagogy that could be used to liberate people from oppression. In his analysis of the educational system in Brazil at the time (and still very much predominant in most parts of the world today), he realized that there was an almost absolute lack of dialogue between teachers and students based on an ill-conceived dichotomy between an allknowing teacher and his/her know-nothing students, whose empty brains served as deposits for the teacher's information. This "Banking System of Education" treated people as objects and reflected a larger culture of silence in which ordinary people's potential were left untapped and indeed deliberately ignored in order to serve the interests of those in power.

Freire attempted to address this situation of injustice by proposing a people's centred "Pedagogy of the Oppressed", in which the act of learning is transitive and all parties learn, i.e., teachers learn from the students and vice versa. Working with marginalized communities, the goal would be for these communities to gain a deeper understanding of their situations of oppression, in what Freire called "Conscientization" or the process of increasing of one's awareness and understanding. Once aware of the reasons behind their oppressive situations, people would then try to find their own solutions and 
strategies for change, i.e., they would become the protagonists of their own lives instead of waiting for other people (political or religious authorities, community leaders, and businessmen, parents) to solve their problems for them.

\section{Conflict}

Conflict is an inescapable reality of social existence. Nations, communities, identity groups, families and even individuals experience conflicts in their interactions with similar constituted entities. All conflicts if not managed well result into violence. A common definition of conflict in the literature on conflict analysis is a situation in which two or more individuals or groups perceive that they possess mutually incompatible goals. Conflict occur when two or more parties perceive that their interests are incompatible, express hostile attitudes, or take, pursue their interests through actions that damage the other parties. These parties may be individuals, small or large groups, and even countries. Interests diverge in many ways ranging from conflicts over resources (territory, money, food energy sources, food and how they should be distributed); power (political decision making processes and representation); identity (cultural, social and political affinities); status (respect and human dignity) and values (religion and ideology).

In spite of the differences between conflict and crisis, they are often used interchangeably. While crises are "a turning point in the course of anything, uncertain time or state of affairs, moment of great danger or difficulty: conflict, on the other hand, is seen as "to be in opposition to another or each other..." (Kesterner \& Ray 2002, p.34). Thus. crises are sudden eruptions of unexpected events caused by previous conflicts. Furthermore, Kesterner and Ray (2002) see conflict as a social factual situation in which at least two parties (individuals, groups, states) are involved and strive for goals which can only be reached by one party, and or want to employ incompatible means to achieve a certain goal. It thus implies struggle over values or claims to status, power and scarce resources in which the aims of the groups or individuals involved are not only to obtain the desired values but to neutralize, injure or eliminate rivals.

Conflicts are not static but possess their own dynamics including spirals of escalation and de-escalation. By observing and reviewing conflicts it is possible to identify phases and turning points in their development which form a general pattern. This is a useful exercise for awareness raising and sensitizing oneself to the consequences of one's action or behaviour in a conflict situation. It can also form the basis for an understanding of what type of approaches or interventions are appropriate at particular stages of a conflict. 


\section{Drama/Theatre for Conflict Transformation}

Transformative theatre practice seeks reforms of pedagogy. Bessette (2011, p.50) avers "we no longer search for safe spaces. Those do not exist and if they did, they are not conclusive to fundamental change. I now look for contested space where to practice pedagogies of discomfort, if it doesn't, we will create them." This statement points out the new ideals of people, space and problems as transformative theatre in the 21th century. It evokes fresh responses of emotions, memories, thoughts about oneself and self experiences. Boal (2000) asserts that theatre is supposed to sway hearts and minds. If theatre has any new purpose of transformation other than entertainment, then it is to show new ways of seeing, to confront us with truth, to make us think in new dynamic directions and even change our behavioural patterns which bring us to the idea of "bringing people first."

Transformative theatre for conflict resolution, therefore, applies well to any set of people that are willing to forget their past situations and join hands to contribute to the ongoing process. The practice itself is a group or collective medium that seeks collaboration to achieve their common goals. It is appropriate for communities and cultures that seek and value narrative and dramatic communication media. For Amollo (2002), it is a better approach for resolving conflict related to underlying structural dilemmas and a means for stimulating issues creatively towards new approaches to problems. Transformative conflict resolution was employed to help change the way the people, religious, government and nongovernmental bodies and the likes perceive value and speak about an act towards each other in the situations they find themselves. The tenet here is that theatre for development offers and points out issues for the people to take actions themselves.

Thus, drama for conflict transformation (DCT) must address the structural injustice and structural oppression that underlie people's misery and powerlessness, as well as the immediate manifestations of conflict in people's personal lives; as evidenced in FUOYE students and Oye-Ekiti indigenes crises. DCT seeks a bottom-up approach to conflict transformation and peace by helping its 'spect-actors' to recognize and name the forces that shackle them in ways that help participants to recognize the personal and community strengths they do have to create positive responses. Through their involvement in DCT, participants can discern and build on foundations for dialogue and tolerance. 


\section{Theoretical Framework}

This study is hinged on Mezirow's (1997) Transformative learning theory. The theory explains the change process that transforms the humans' frames of reference. Mezirow theory defines frames of reference as the structures of assumptions through which we understand our experiences. They selectively shape and delimit expectations, perceptions, cognition, and feelings. According to this view, actions and behaviours will be changed based on the changed perspective. This theory informed Augusto Boal's views on forum theatre that provides skeptical, inquisitive, comic and optimistic theatre involving spectators and performance in search of community integrity and cohesion (Boal, 2000). The tenets of this community approach is that the theatre depends so much on the people, their culture, the communities as a motivating factor to facilitate social change. The theoretical premise of this technique is centred on empowering the communities to take active role in the theatre and society and provoking change and participation. The tenet here is; that theatre gives room for decision making and active involvement in handling of issues which offer the people the opportunity to be part of their problems and to find ways to resolve them by themselves.

Jack Mezirow's Transformative learning theory thus has one of its core premises on adults specifically students changing their warped or dysfunctional worldview after a critical self-reflection on their beliefs and collective experiences. The suitability of this theory is not debatable here as it could be deduced that the actors in this scenario face a "disorientating dilemma" to cause a reflection of held beliefs with a view to changing them.

\section{The FUOYE Students and Host Communities/Indigenes Conflict: The Profile}

Conflict as a phenomenon can occur in variegated forms. It could occur at the intra-personal or inter-personal levels. It could also express itself at the group level, local, state or national levels. Conflict can also assume international dimension when such situation is between two countries. It may be a feature common to all forms of conflict; which implies that it must express itself in a transmissible form. However, between FUOYE students and the host communities/ indigenes (Oye-Ekiti, and the other neighboring villages mentioned earlier), the most prominent form in which conflict seems to be expressed is through violence. Oye-Ekiti is a semi-urban area, the headquarters of Oye-Ekiti local government area (LGA) of Ekiti State, and a suburb of Ado-Ekiti the state capital. 
The host community is stifled by hardship thereby making the struggle for survival in the area intense. This situation seems to inform the spirited effort put up by the people to have some measure of control of their 'God-given opportunity.' Situating FUOYE in their community is a means to liberate them from poverty; an agenda that is pursued with all vehemence. This situation underscored by the indigenes' outrageous rents; indiscriminate rent increments - thereby leading to illegal ejection of students from their rented apartments. Hike in electricity bills - whereas power is not available, yet tenants must pay. Hike in prices of goods and services - that manifested in the hike in price of transportation in Oye-Ekiti and its environs; which eventually metamorphosed into the bloody violence between the FUOYE-students and the Oye-Ekiti indigenes.The student flaunting their prestige of being university students with youthful exuberance and delinquencies - involving in all manner of vices, i.e., smoking Indian hemp (Igbo or weed) are issues of concern to the indigenes. Keeping late night movements, all manner of uncleanness, amorous relationship among the students, discourteousness, unusual student restiveness, disrespectfulness which the indigenes complained about the students; are partly the issues causing the FUOYE students/ indigenes clashes. Thus, the primary causes of conflict between the FUOYE students and their host communities are the struggle for recognition and respect from both parties. There is a perceived oppression from both parties, leading to violent clashes. For instance, students keeping late night movement (i.e. from 9:30 PM upwards is regarded as late night in Oye-Ekiti and its environs). Students who are caught moving around in the late night are punished by being paraded throughout the night till dawn. Once this happen to any student in the community, the body of students (union) sees it as an act of oppression.

Equally, the indigenes - landlords/landladies see students' refusal to clean their houses and environment and pay their electricity bills and rents promptly as oppression. Most of them frown at the disrespectful attitude of the FUOYE students which they perceive as as a form of oppression. Another issue that raises tension and conflict between the FUOYE students and Oye-Ekiti indigenes is the unavailability or scarcity of banking facilities in the community. A graphic example is a situation in which an indigene goes to the United Bank for Africa Automated Teller Machine (UBAATM) stand in Oye-Ekiti, the only banking facility in the community and meets over fifty FUOYE students on the queue, waiting to withdraw money too. The Oye-Ekiti indigene because of the Omonile's (indigene's) mentality would want to use the ATM Machine first. It is this kind of intimidation or oppressive tendency that frequently results to violent conflicts. The Oye-Ekiti 
indigenes also perceive the FUOYE students attitude as bad influences on their children and wards. Many of the indigenes feel oppressed and intimidated when some of the students show-off their affluence. The same way the FUOYE students perceive hike in prices of goods and services, electricity bills as exploitative. The paradox of this scenario is that both parties see themselves as being oppressed.

\section{Devising the Forum Theatre Play: The Oye-Ekiti Forum Theatre Skits}

Participants - the 200 level students of the Department of Theatre and Media Arts and the youths of Irona Quarters, Oye-Ekiti started the forum theatre by discussing the issues of oppression in their lives. They express the issues as they experience them in their compounds/ homes and the community. Within the context of the workshop, participants share scenarios related to conflict in their community, or moments in which they were not able to achieve peace, within a group. After listening to one another's stories, participants thereafter choose one or two stories that illustrate problems which they would like to find solution for.

The stories are then rehearsed, making clear who is the oppressor (antagonist) and the oppressed (protagonist) - although Boal used the terms oppressor/oppressed, we will use antagonist/protagonist in this study. During the rehearsal process, participants illustrate key moments of potential intervention, where a different choice by the protagonist could change the outcome of the scenario. The scenario is performed up to the moment of crisis. There is no resolution. The performance is demonstrated one time through without stopping, then an audience/performer mediator called the Joker tells the audience that the story will be played back again, and at any point in the story at which they feel there could be a different action to create a different outcome, individual audience members may yell 'stop.' The actors freeze. The individual audience member will then come up to the stage, take the place of the protagonist and continue from that point in the action, playing out their alternative idea to create an ideal outcome for the scenario.

Interactive session: participants then begin discussion of issues of oppression in their lives as captured in the previous session (as earlier noted). Within the context of the workshop, participants drawn from among FUOYE students and Oye-Ekiti indigenes share scenarios related to conflict in their community, or moments in which they were not able to achieve peace within a group. After listening to one another's stories, participants select almost all the stories which illustrate problems as earlier raised which they would like to find 
solutions to. The stories were then rehearsed, making clear who is the oppressor (antagonist) and the oppressed (protagonist).

\section{Synopsis of the Oye-Ekiti Forum Theatre Skit}

The story revolves around Mama Shola, an Oye-Ekiti indigene and landlady, who lives with his son Shola in the same house. She rents some part of the building to some FUOYE students. These tenants, that is, FUOYE students exhibit all kinds of negative attitudes which always put both parties at loggerheads. The students' attitudes range from: the female students wearing skimpy dresses (indecent dressing), smoking (Indian hemp) in public, keeping late night; thereby negatively influencing her son, Shola, refusal to clean their rooms and by extension the compound they reside in, prostitution among the female students among other vices. Mama Shola on her own part being a good mother continues to correct them against these vices time and again; though in a hash manner. The FUOYE students on their part are not willing to heed Mama Shola's advice, thereby exacerbating the situation. Subsequently, Shola joins the gang of bad boys; thereby causing more heartache for Mama Shola. Every other issue mentioned earlier are re-enacted as play-within-a-play and the forum for discussions follows immediately.

\section{Discussion of Findings}

This study investigated programme outcomes of drama for conflict resolution, using forum theatre. The FUOYE students/Oye-Ekiti conflict resolution based programme was a twelve weeks programme that employed a combination of role play and interactive drama to build conflict resolution skills. The programme was developed partly in response to Goal 7 of the National Education Goal Panel report (NEGP, 1997), which urges for a decrease in violence in public schools and learning environment. This evaluation is timely, given that recent estimates that have documented an increase in school-related violence within Nigerian higher institutions of learning and a paucity of research on how skill-based approaches using interactive drama create change in conflict resolution strategies. The results of the present study give support to all the objectives set for this study. With regard to the first objective, there was an increase in knowledge regarding effective strategies for conflict resolution among FUOYE students and OyeEkiti indigenes. Responses indicated that students learned to identify and express their feelings as well as the importance of thinking before acting. It may be noted that Nigerian students are restive; however, with replication of intervention programmes such as this, it is likely that restiveness would reduce among Nigerian students, if the project is properly planned and executed. 
The foregoing outcome corroborates Bandura's social learning theory (1977) that suggests that people are more likely to adopt a modeled behaviour (i.e., new conflict resolution styles) if the model is similar to them. Although, there is no way to know for sure if this explains the difference in acquired knowledge across cultures, it is recommended for all conflict resolution programmes that utilize role play and interactive drama that the materials and role plays used, as well as the facilitators hired to deliver the programme, are relevant and credible to the students/participants and closely represent conflict that is not specific to certain cultures. There was partial support for the second objective that students would show a decrease in their level of aggression, but that depended upon age level and the type of aggression exhibited. Specifically, teenagers/students showed decrease only in their levels of relational aggression (e.g., spreading rumours). Adolescent students showed a decrease both in their levels of relational aggression and physical aggression (e.g., fighting). There are several possible explanations for the finding. It is possible that significant differences were not observed for teenagers/students in terms of physical aggression because their levels of physical aggression were low to begin with, especially compared with adolescent students. Alternatively, perhaps in teenagers, the primary mode of aggression is relational rather than more overt aggressive strategies. Some research suggests that this might be the case, with relational aggression being equally as harmful as physical aggression, particularly among girls (De Voe et al., 2005).

Partial support was found for the third objective that students would increase their level of effective communication. Specifically, only adolescent students showed an increase in their skills while levels among teenagers/students remained relatively stable. Considering the combination of lower levels of communication, lower levels of physical aggression, and higher levels of relational aggression, it appears that teenagers may be a time when conflict increases, but is addressed more covertly. Perhaps, when covert tactics no longer work, physical aggression occurs which explain the reason for the higher rates of physical aggression among adolescent students. There is some research suggesting that this might be the case (Dellasega, 2005), suggesting that adolescent students are more likely to use direct confrontation rather than indirect approaches such as spreading rumours. The results highlight the need for the school, universities' students' affair division to be aware of the equally threatening presence of relational aggression, particularly among teenagers: with an understanding that this type of covert aggression can also be harmful as overt aggression in terms of its influence on the personal and academic development of students. With the possibility that relational 
aggression may be a precursor to physical aggression, early and appropriate assessment and intervention is necessary to curtail the escalation of conflict and the need to avoid negative outcomes.

The findings need to be considered in light of a number of merits. One merit of the study is that information about programme evaluation outcomes was collected from both the FUOYE student and the OyeEkiti indigenes - consisting of adolescents of ages (18 to 55 years) who participated in the forum theatre programme. In future work, it may be necessary to compare school records (e.g. declines in campusbased fights and assaults) directly with students' reported behaviours and attitudes to assess whether there are differences across reporters. Also, a qualitative component to a future evaluation design would also be an important addition to document students' and lecturers' direct experiences of the programme and instances in which they applied the conflict resolution strategies. Furthermore, the pre-post test was a self-reported measure. The use of self-report is a valid form of assessment for purposes of research and can yield useful information given that students understand what they are asked and are motivated to provide accurate information. Although, all self-report measures run the risk of false reporting, previous research has confirmed the value of self-reports as are viable indicator of behaviour (Hindelang, Hirschi \& Weis, 1981). Since the evaluation design was a pre-post design, the long-term impact of the programme could reliably be determined.

Among others things, the findings suggest that the drama for conflict resolution programme has helped students/Oye-Ekiti indigenes who participated to develop effective alternatives to deal with conflict. An assessment that was carried out in September 2019, that is, a space of over a year also revealed that if the programme is sustained; the long-term effect would be a reduction in fighting and conflict situations that would improve relationships among student participants. Furthermore, conflict resolution programmes must emphasize an incorporation of cultural diversity into the programme as recommended by current best practices guidelines (American Psychological Association, APA, 2002), including both the personnel delivering the programme as well as the content of the programme itself. Perhaps, with increased attention and refinement to the perennial problem of schools' conflict, universities' administrators, guidance counselors, and students can work toward the worldwide goal of reducing violence in schools. 


\section{Summary of Oye-Ekiti Forum Theatre Resolution}

1. It was unanimously resolved that Mama Shola, the landlady should correct the FUOYE students in love; by so doing, the FUOYE students might turn over a new leaf.

2. The FUOYE students should always take Mama Shola's advice because she is like a mother figure to them and every parent wants the best for their children.

3. The FUOYE students should listen to their parents and the elderly advice and desist from all forms of vices for their own good and the society's good.

4. Cleanliness is nearest to godliness, therefore, every FUOYE students should keep a clean home and environment.

5. On keeping late night, FUOYE students should keep to the rules for security purposes.

6. On hike in prices of rents, electricity bills, goods and services, FUOYE students should bear with the Oye-Ekiti indigenes because that is their only source of livelihood and they are also struggling for survival too.

7. Conclusively, both parties should be accommodative; tolerate one another. Oye-Ekiti indigenes are also tertiary education students in other communities, Oye-Ekiti indigenes, landlords and landladies at home should treat FUOYE students the way they would want their children abroad be treated.

8. There should be periodic meetings between management of FUOYE, the FUOYE students union and the transport unions to forestall future violence.

\section{Conclusion}

It is pertinent that note that conflicts irrespective of the nature and causes are part and parcel of human existence. Strife, disagreement and hatred can erupt at any time as people sojourn and struggle for space, identification, political power and limited resources in society. Hence, the tendency for conflict to erupt among people that are living together peacefully is possible. The FUOYE students and Oye-Ekiti indigenes conflict is a typical example of the above.. However, the role of theatre in such a situation is critical. In this paper we have established that theatre has a role to play in resolving situations by mapping out the path to peace and reconciliation. It argued that forum theatre (FT) could be an effective tool for conflict resolution of any magnitude. FT has emerged to be an effective weapon in raising the consciousness 
of the people towards the maintenance and sustenance of peace and peace-building. Therefore, a practical schema for theatre intervention must be based on the analysis of what went wrong, why it went wrong and how to deal with the perceptions associated with the feeling of those who feel wronged through performance.

\section{References}

Albert, I. O. (2001). Building peace, advancing democracy: Experience with third-party interventions in Nigeria's conflicts. Ibadan: John Archers (Publishers) Ltd.

Amollo, M. (2002). From playing to learning to change: Theatre in conflict transformation and peace building. Nairobi: Amani People's Theatre.

APA. (2002). Guidelines on multicultural education, training, research, practice, and organizational change for psychologists. Washington, DC: APA.

Baim, C., Brookes, S. \& Mountford, A. (2002). The geese theatre handbook: Drama with offenders and people at risk. Hampshire: Waterside Press.

Bessette, G. (2011). Participatory development communications for natural resource management. Ratchaburi Province, Thailand: El Servey.

Boal, A. (2000). Theatre of the oppressed (translated by C. \& M.O Leal MC Bride). New York: Theatre Communications Group.

Hindelang, M. J., Hirschi, T., \& Weis, J. G. (1981). Measuring delinquency. Beverly Hills: Sage.

Dellasega, C. \& Adamshick, P. (2005). Evaluation of a programme designed to reduce relational aggression in middle school girls. Journal of School Violence, 4, 63-76.

De Voe, J. F., Peter, K., Noonan, M., Snyder, T. D., \& Baum, K. (2005). Indicators of school crime and safety. Washington, DC: U.S. Departments of Education and Justice.

Kesterner, B. P. \& Ray, L. (2002). The conflict resolution training programme leader's manual. San Francisco, CA: JosseyBass.

Mezirow, J. (1997). Transformative learning: Theory to practice. In P. Cranton (Ed.). New directions for adult and continuing education (pp. 5-12). San Francisco, CA: Jossey-Bass.

McTaggart, R. (1997) Participatory action research: International contexts and consequences. Albany, NY: State University of New York Press. 
National Education Goals Panel. (1997). The national education goals report: Building a nation of learners. Washington, DC: Government Printing Office.

Turnes, M., Gennifer, J., \& Cliff, L. (2005). The impact of armed conflict on poverty and development. Retrieved 15 September 2018, from http://www.unap.org/epr/documents/armed-violence/ AVIDI-syn-thesis Report PDF. 